\section{rev Psi}

Revista de Psicología (UNLP)

https://revistas.unlp.edu.ar/revpsi

\title{
Temple Grandin: la interrupción del lenguaje y lalengua en el autismo
}

\author{
Patricio Álvarez Bayón $n^{1,2,3,4}$ \\ Correspondencia \\ patricioalvarezb@gmail.com
}

\section{Filiaciones institucionales}

${ }^{1}$ Escuela de la Orientación Lacaniana (EOL, Argentina) ${ }^{2}$ Facultad de Psicología, Universidad de / Asociación Mundial de Psicoanálisis (AMP) Buenos Aires (UBA, Argentina)

${ }^{3}$ Instituto Clínico de Buenos Aires (ICdeBA,

${ }^{4}$ Universidad de San Martín (UNSAM, Argentina)

Argentina) [Maestría en Clínica Psicoanalítica]

\section{Resumen}

El texto hace un análisis psicoanalítico del texto autobiográfico de Temple Grandin "Atravesando las puertas del autismo", para teorizar sobre el autismo, la diferencia entre los conceptos lacanianos de lalengua y el lenguaje, el concepto de forclusión del agujero, y el "pensamiento en imágenes" propio de algunos autistas. Ubica además la diferencia entre autistas de alto nivel y autistas severos en función de cómo logran ingresar al lenguaje o quedan detenidos en relación a lalengua.

\section{Palabras clave}

autismo | forclusión del agujero | lalengua | lenguaje | borde | pensamiento en imágenes

\section{Cómo citar}

Álvarez Bayón, P. (2021). Temple Grandin: la interrupción del lenguaje y lalengua en el autismo. Revista de Psicología, 20(1), 76-88. HTTPS://DX.DOI.ORG/10.24215/

$\begin{array}{ll}\text { Proceso editorial } & \\ \text { Recibido } & \text { 1ra decisión } \\ 6 \text { sep. } 2020 & 10 \text { sep. } 2020 \\ \text { Aceptado } & \text { Publicado } \\ 27 \text { jun. 2021 } & 30 \text { jul. 2021 }\end{array}$

Coordinadora del dossier

María Cristina Piro (Facultad de Psicología UNLP, Argentina).
ISSN

2422-572X

Licencia

Licencia de Cultura Libre CC-BY 4.0

(Compartir - Adaptar - Atribuir)

Entidad editora

RevPsi es una publicación de la

Facultad de Psicología (Universidad

Nacional de La Plata, Argentina) 


\section{Temple Grandin: a perturbação da linguagem e de alíngua no autismo}

\section{Resumo}

O texto faz uma análise psicanalítica do texto autobiográfico de Temple Grandin "Atravessando as portas do autismo", para teorizar sobre o autismo, a diferença entre os conceitos lacanianos de alíngua e o linguagem, o conceito de forclusão do buraco e o "pensamento em imagens" típico de algumas pessoas autistas. Também localiza a diferença entre autismo de alto nível e autismo severo com base em como eles conseguem entrar na linguagem ou ficam detidos em relação a alíngua.

\section{Palavras-chave}

autismo | forclusão do buraco | alíngua | linguagem | borda | pensamento em imagens

\section{Temple Grandin: the disruption of language and lalangue in autism}

\section{Abstract}

This text makes a psychoanalytic analysis of Temple Grandin's autobiographical text "Emergence: labeled autistic", to theorize about autism, the difference between the Lacanian concepts of lalangue and language, the concept of forclussion of the hole, and the concept of "thinking in images", a characteristic of several autists. It also locates the difference between high-level autism and severe autism based on how they manage to enter the language or are detained in their relation to lalangue.

\section{Keywords}

autism | forclussion of the hole | lalangue | language | border | thinking in pictures 
La biografia de Temple Grandin, publicada en el libro "Atravesando las puertas del autismo" (Grandin, 2006), nos permite extraer una serie de enseñanzas para una conceptualización psicoanalítica del autismo.

Su relato, rico en precisiones, anécdotas y descripciones de cómo percibe y siente un autista, cuáles son sus centros de interés, qué relación establece con los otros, etc., nos hacen entrar en su mundo y entender muchas de sus particularidades. Nos centraremos, en ese relato, en algunos puntos que hacen a su relación al lenguaje, al borde y al cuerpo.

Pero en principio, remarquemos algunos aspectos por los que Temple Grandin es conocida: considerada una autista de alto nivel, es famosa por la construcción de máquinas para el ganado que se utilizan industrialmente, tiene un doctorado en psicología animal, tiene una Fundación para orientar a padres con hijos autistas, da conferencias sobre autismo, y se filmó en el año 2010 una película sobre su vida a partir de este libro, llamada Temple Grandin, que ganó un Globo de Oro.

\section{El borde y la forclusión del agujero}

El primer efecto de la forclusión del agujero, tesis causal que establece Eric Laurent sobre el autismo en su libro La batalla del autismo (Laurent, 2013), es que en la medida en que no se establece el agujero que lo simbólico produce en lo real, y por lo tanto no se constituye un borde topológico entre lo simbólico y lo real, no es posible para el autista construirse un cuerpo y un yo en el registro imaginario.

El segundo efecto, es la dificultad para establecer una diferenciación entre lo que los kleinianos intuitivamente llamaban el yo y el no-yo, es decir, el borde topológico que establece en lo simbólico la diferencia entre el sujeto y el campo del Otro. Esto tiene efectos también en el plano imaginario, sobre la construcción del borde entre el yo y los semejantes.

Los primeros años de vida de Temple Grandin testimonian de esta dificultad. Sus primeros recuerdos hacen mención constante a la percepción, al cuerpo y a la relación con los otros.

Tenía las conductas típicas del autismo: obsesión con los objetos que giran, preferencia por la soledad, berrinches, incapacidad de hablar, sensibilidad a los ruidos sorpresivos, sordera aparente e intenso interés por los olores. Era una niña destructiva, que pintaba la habitación con sus excrementos, arrojaba objetos y los rompía. Disponía de tres o cuatro palabras hasta empezar con la terapeuta de lenguaje a los cuatro años.

En el plano del cuerpo, la dificultad con el borde se observa desde el inicio en su sensibilidad especial a los ruidos y a las texturas, que la hacían evitar todo contacto. La mayoría de sus recuerdos infantiles se establecen en relación a estos dos elementos: el oído y la piel. 
En relación a los otros, establece una separación clara que ubica también la dificultad con el borde: "mi mundo" y "el mundo de la gente". En su mundo, "yo disfrutaba dando vueltas y también haciendo girar monedas o tapas. Mientras contemplaba absorta el movimiento, no veía ni oía nada más. Las personas que me rodeaban eran invisibles. Ni siquiera un ruido fuerte y repentino podía sacarme de mi mundo". En el otro mundo, todo era difícil: "pero cuando estaba en el mundo de la gente, era extremadamente sensible al ruido (...) para mí era una pesadilla de ruidos que invadían mis oídos y mi alma" (Grandin, 2006, p. 26).

A los cuatro años, la terapia de lenguaje le permitió hablar mínimamente. A los cinco ingresó al jardín, pero no podía soportar la bulla escolar y debía aislarse, y su dificultad para entender las sutilezas del lenguaje le impedía socializarse.

En lo que hace a la sensibilidad corporal, no soportaba muchas texturas de ropa o de objetos, y menos aún el contacto corporal con las personas. Desde muy niña recuerda las crisis de excitación que la llevaban a estados de desesperación. No podía detener su necesidad de algo que la calmara, sin saber de ningún modo qué le pasaba o qué podía calmarla. A los siete años:

(...) comencé a soñar con un aparato mágico que proporcionara estimulación a mi cuerpo ejerciendo sobre él una presión placentera. En mi imaginación, ese maravilloso aparato (...) estaría disponible en todo momento para tranquilizarme. Hoy sé que mi visión infantil representaba mi búsqueda de algún medio que satisficiera el anhelo de estimulación táctil de mi sistema nervioso dañado (...) yo ansiaba un contacto tierno. Hubiera dado cualquier cosa por ser amada, por ser abrazada. Al mismo tiempo evitaba el contacto, como en el caso de mi tía obesa y demasiado afectuosa. Recibir sus demostraciones de afecto era para mí como ser engullida por una ballena (...) Deseaba y rechazaba al mismo tiempo. Mi sistema nervioso dañado me aprisionaba. Era como si una puerta de vidrio corrediza me separara del mundo de amor y de comprensión humana. Hay un punto de equilibrio entre enseñar a un niño autista a disfrutar del contacto y provocarle el temor a ser engullido (...) La conducta de evitación del contacto y la hipersensibilidad son semejantes. La ropa de lana, por ejemplo, me resulta intolerable incluso en la actualidad (...) Nuestros cuerpos claman por contacto humano, pero cuando se produce lo rechazamos en medio del dolor y la confusión. Sólo pasados los veinte años fui capaz de estrechar la mano de otra persona o de mirarla directamente a la cara (Grandin, 2006, p. 34).

En relación a ese borde topológico que no se produce estructuralmente, remarquemos aquello con lo que fantaseaba, al modo de un anhelo, y que continuó a través de los años: "Mientras me dedicaba a soñar despierta durante las clases de tercer grado, imaginé un tipo diferente de máquina de bienestar. Se trataba de una 
caja semejante a un ataúd. Yo me introduciría en ella gateando a través del extremo abierto..., y luego, otro tipo de máquina: "imaginé un traje inflable capaz de aplicar presión a mi cuerpo. Lo que me dio esta idea fueron los juguetes de plástico inflables que se usaban en la playa" (Grandin, 2006, p. 36).

No se trata de una ensoñación diurna, amorosa, ni sexual. Tampoco se trata, en una niña de 7 y 8 años, de una fantasía lúdica al estilo de las princesas o los cuentos infantiles. Se trata de un fantaseo en relación a una máquina, que sirve para contener algo del cuerpo, es decir un borde, que la tranquilizaría:

Pero en la niñez, como no disponía de ningún aparato mágico que me proporcionara bienestar, me envolvía en una frazada o cubría mi cuerpo con almohadones de sofá para satisfacer mi deseo de estimulación táctil (...) a veces llevaba láminas de cartón como un hombre-sándwich porque me agradaba la presión que ejercían sobre mi cuerpo (Grandin, 2006, p. 35).

La no constitución estructural de un borde, no permite alojar el goce dentro de los límites del cuerpo, porque éste no se constituye. Esa imposibilidad de alojar el goce produce en el autismo las crisis de excitación: "Quizá si yo hubiera tenido un aparato mágico productor de bienestar podría haberme servido de su calor y su presión en lugar de tener berrinches" (Grandin, 2006, p. 37).

Lo interesante es que años más tarde, ella construirá esa máquina. Y que mediante ella, además, se hará famosa. Pero volveremos sobre esto más adelante.

Podemos entonces remarcar hasta el momento, que esta sensibilidad especial expresa bien las múltiples implicancias de la dificultad para la subjetivación de un borde topológico, y observar que la dificultad en relación al borde se realiza, como mínimo, en cuatro niveles:

- a nivel del sujeto y el Otro -mi mundo y el mundo de la gente-, en el plano simbólico,

- a nivel de la relación entre el yo y sus semejantes -la sensación de ser engullida, la no diferenciación entre las texturas molestas como la de la lana y los abrazos de las personas, es decir entre los objetos y lo humano -, en el plano imaginario,

- a nivel de la sensibilidad primaria -las texturas y los ruidos-, en el plano simbólico-imaginario,

- a nivel de la construcción del borde corporal y la localización del goce -la evitación del contacto, las crisis de excitación corporal y la fantasía de construir la máquina de presión para alojar esa excitación-, en el plano simbólico-real. 


\section{El lenguaje y la forclusión del agujero}

Con los años, observamos un progreso muy importante en sus aptitudes de lenguaje y sociales. En relación al diagnóstico, en el DSM es un Trastorno del espectro autista, y en relación al diagnóstico psiquiátrico clásico no sería estrictamente un autismo de Kanner, sino más bien un síndrome de Asperger, en el cual las capacidades de lenguaje y de socialización son relativamente altas. Para el psicoanálisis es un autismo de alto nivel, y observamos que año a año, sus capacidades se van ampliando y modificando.

A nivel del lenguaje, debemos resaltar una consecuencia de la forclusión del agujero diferente a las anteriores.

Lacan señaló en su Seminario 1 y en la Conferencia en Ginebra veinte años más tarde, que hay algo en el autista que se congela, que se detiene, en relación al lenguaje. En su última enseñanza, postuló que lo simbólico, el sistema de significantes en el cual se define al inconsciente estructurado como un lenguaje -sistema que tiene reglas de oposición, de jerarquía y de ordenamiento metafórico o metonímico muy precisas-, está precedido por un tiempo lógico anterior, que es el de lalengua. Lalengua no es un sistema como el lenguaje, sino que es definida por Lacan como una integral de equívocos compuesta por palabras sin sentido -los S1- que marcan el cuerpo produciendo acontecimientos, en un tiempo lógico anterior al de la construcción del lenguaje. En lalengua los S1 no tienen relación con el S2, no forman un sistema ordenado, sino lo que Lacan llama un enjambre de S1: "El S1, el enjambre, significante amo (...) no es un significante cualquiera (...) El uno encarnado en lalengua es algo que queda indeciso entre el fonema, la palabra, la frase y aun el pensamiento todo" (Lacan, 1992, p. 173).

Por eso Lacan define en su última enseñanza al lenguaje como una elucubración de saber sobre lalengua, porque el lenguaje se construye en un segundo tiempo lógico, encadenando los S1 con los S2. Pero su núcleo y origen es lalengua, primera forma de lo simbólico.

Ahora bien, lalengua tiene la función de agujerear lo real, y a partir de ese agujero puede construirse el anudamiento de los tres registros. Ese agujereamiento es lo que Lacan llama el troumatisme, juego de palabras con el que une el trauma que produce lalengua, con el agujero (trou) en lo real.

Ese agujereamiento es lo que permite el pasaje de lalengua al lenguaje. Sin ese agujereamiento no se produce el pasaje. En el autismo, ese agujero está forcluido, y por eso el autista permanece en el campo de lalengua. A esto se refiere Lacan cuando dice que hay una detención, un congelamiento, algo del lenguaje que no se pone en marcha: el pasaje de lalengua al lenguaje no se produce estructuralmente y entonces algo del lenguaje queda detenido.

Por esta razón, Laurent dice que el autista permanece en el murmullo de lalengua, porque la forclusión del agujero no le permite encadenar los S1 de lalengua al sistema de saber del lenguaje, formando cadenas significantes. 
Esto, por supuesto, no quiere decir que los autistas no puedan hablar. Quiere decir que el autista no necesariamente habita el campo del lenguaje. Puede habitarlo, o no, según ciertas operaciones que pueda hacer con el lenguaje.

El tratamiento del lenguaje que hace Temple Grandin nos permite entender una de las posibles operaciones que puede realizar un autista. Temple lo llama, tal como se llama uno de sus libros: "pensar en imágenes". En efecto, observamos una operación con el lenguaje que no es la habitual según la lingüística.

Intentemos explicarlo: habitualmente, el lenguaje se construye como un sistema de operaciones significantes que se relacionan entre sí a partir de ciertas leyes de oposición y combinación -por ejemplo, la metáfora y la metonimia, entre otras-. Estas leyes, que los lingüistas establecieron, son las que permiten generar el significado de esos significantes. Es decir que el significado de una palabra depende siempre del contexto de combinación y oposición de los significantes, es un efecto de la cadena significante.

Estas leyes permitieron a Lacan, a partir del estudio de las leyes de combinación del inconsciente enunciadas por Freud, decir que el inconsciente tiene la misma estructura que un lenguaje, que sus reglas funcionan igual. Y también esto permitió a Lacan decir que el inconsciente funciona como un lenguaje en la neurosis, pero no en la psicosis. Lacan establece una diferencia al decir que la neurosis es "un puro y simple hecho de lenguaje" -dado que todas sus operaciones, tanto los significantes que se reprimen como los que retornan de lo reprimido, siguen dentro de lo simbólico-, mientras que en la psicosis hay un "decir psicótico" en el que ciertas palabras toman un peso particular, se desprenden de la cadena significante, dado que en ellas lo real tiene un peso particular. Lacan llamó a esto "significante en lo real", dado que esos significantes no pasaron por la represión sino por la forclusión del nombre del padre, el mecanismo fundante de la psicosis.

Ahora bien, en el autismo observamos algo diferente al significante en lo real de la psicosis o al significante encadenado de la neurosis. El efecto estructural de la forclusión del agujero es esa dificultad en el pasaje de lalengua al lenguaje, por el que el autista permanece en el murmullo de lalengua.

A diferencia de esto, Temple construye el lenguaje de un modo diferente. Parte del significado, de la imagen, y a partir de él construye las oposiciones significantes.

Uno de sus problemas, entonces, será cómo articularse al lenguaje, cómo construirse un lenguaje al no disponer de él por estructura. Este "pensar en imágenes" que mencionamos nos da una pauta de cómo hacen algunos autistas para articularse a él.

La imagen es una de las piezas centrales del registro imaginario, junto al yo, el narcisismo, etc. La imagen está íntimamente ligada al significado, que como dijimos antes, depende del encadenamiento significante y es un efecto de éste, por lo que la imagen es variable, modificable, desplazable. Sólo ciertas imágenes cobran una fijeza especial, aquéllas ligadas al fantasma en la neurosis. 
La imagen además cobra un valor libidinal que Lacan señaló en sus primeros seminarios, demostrando que ciertas significaciones cobran para el niño un valor especial a partir de cuáles sean los significantes asociados a ellas.

Este valor relativo de la imagen, dependiente de la cadena, es correlativo de la primera enseñanza de Lacan donde hay una supremacía simbólica. En su segunda enseñanza, cuando pone el acento sobre los nudos donde hay una equivalencia de los tres registros, pueden pensarse otros modos de anudamiento en los cuales el registro imaginario puede cobrar otra importancia.

De este modo, el pensar en imágenes de Temple Grandin y de otros autistas, como Daniel Tammett, les permiten uno de los modos de hacer ese pasaje de lalengua hacia el lenguaje, construyéndose un sistema simbólico propio.

El primer recuerdo infantil que Temple Grandin cuenta en su libro es de sus tres años. Su madre llevaba a ella y a su hermana en auto por la autopista, ella tenía puesto un sombrero que odiaba por su textura, se lo saca, la madre le insiste en que se lo ponga, y ella logra tirar el sobrero por la ventanilla abierta de su madre. Su madre intenta agarrarlo mientras maneja, se sale de pista, y son arrollados por un camión. Ella sentía con placer el movimiento del auto que giraba en círculos. Allí recuerda sus primeras palabras: hielo! (ice), cuando miraba fascinada como estallaba el parabrisas del auto.

J.-C. Maleval ha comentado escenas semejantes al situar cómo el autista se resiste a articular el objeto voz a la palabra, como modo de no inscribir la operación de alienación. Demostró cómo en ciertos momentos de angustia extrema, un autista puede soportar por un instante el peso de la enunciación, articulando la voz con la palabra, y decir por ejemplo luego de años de mutismo: "devuélveme mi pelota!".

Pero además, podemos remarcar en esta escena que, además de la angustia y la enunciación como señala Maleval, el dato que le permite decir la palabra hielo es la imagen de los vidrios que caen sobre ella. Hielo, es una de las palabras-imagen que le permitieron comenzar a hablar.

Sus palabras iniciales eran "hielo", "ir", "mío” y "no". Las ubica como palabras imagen: partía de su significado para poder pronunciarlas. Esta asociación, que no parte de la oposición lingüística entre significantes (significante-significante), sino significantesignificado, le impidió por un lado avanzar en la rápida adquisición del lenguaje como los demás niños, pero al mismo tiempo fue su recurso para empezar a hablar.

De este modo, ella señala el pensar con imágenes como uno de los recursos fundamentales que le permitieron hablar y entender el lenguaje de los otros.

A los cinco años empezó el jardín de infantes. "Por fortuna no me daba cuenta de hasta qué punto era diferente de los demás. Yo no hablaba como los otros niños. No comprendía las sutilezas del lenguaje." Pese a que su terapia del lenguaje, acompañado por su recurso de pensar con imágenes, le permitía entender el sentido concreto de las palabras, las sutilezas del lenguaje le eran imposibles. 
Esta dificultad la llevaba a hablar permanentemente de sus temas de interés, que estaban en el plano del pensar con imágenes, o bien a permanecer callada. Desde cuarto grado se fijaba en un tema perseverativamente, sin poder salir de eso. Por ejemplo, la campaña electoral de un gobernador de la que no paró de hablar durante meses, o la obsesión de formular preguntas constantemente: "era capaz de hacer una y otra vez la misma pregunta, esperando con placer oír la misma respuesta. Si un tema determinado me intrigaba, le dedicaba toda mi atención y hablaba de él sin parar". "Incluso de noche, estando en la cama, tenía que hablar: contarme cosas a mí misma en voz alta".

Otra de las dimensiones del pensar en imágenes fue la creación de personajes imaginarios en la pre-pubertad. Se trata de un esbozo de lo que llamamos el doble real en el autismo, un doble fantaseado que les permite imaginarizar un guión determinado. En algunos casos, como en Donna Williams, esos dobles reales tenían nombre y toda una vida fantaseada. En el caso de Temple Grandin se trata de un esbozo de un doble real, no tuvo la pregnancia que tuvo en otros casos. Pero está ubicado en el plano del pensar con imágenes, dado que le permitía simbolizar situaciones que vivía, por ejemplo su propia conducta traviesa o de berrinches, pero ubicadas en un personaje: "Uno de los principales personajes de mis relatos ficticios era Bisban, un actor. Lo mejor que tenía mi Bisban era su capacidad para controlar cosas. Yo quería controlar cosas, y Bisban era mi otro yo. Controlaba las persianas, el termostato, la luz de la heladera. Pero cometía también travesuras, como atar los cordones de los zapatos de mi padre o poner sal en la azucarera. A veces, cuando me contaba a mí misma en voz alta historias de Bisban, no podía parar de reír". "Cuando tenía 11 años mi reparto de personajes había aumentado, y a menudo Alfred Costello participaba en las historias que yo imaginaba. Alfred, una persona real, era uno de los alumnos de mi clase y se pasaba molestándome (...) En mis historias Alfred arrojaba desperdicios en la escuela o le sacaba la lengua a la maestra. Yo reía cuando me contaba esas historias en voz alta. Y cuando en mis historias Alfred era atrapado, me reía a más no poder".

En la pubertad, las modificaciones corporales se presentaron como un problema a tratar con imágenes. "Un chico, que tendría unos años, le dijo a su amigo: No te molestes en mirar a la recién llegada, no tiene tetas. Tetas? Repetí, y los chicos se rieron. El resto de la tarde la palabra tetas fue mi favorita. Me encantaba pronunciarla, la repetía sin cesar". Esa tarde una chica le dijo que las mujeres tienen tetas para alimentar a sus bebés. ¿Entonces los muchachos no quieren alimentar a sus bebes?, le preguntó. Ella le dijo que los muchachos tienen otra cosa. ¿Qué cosa?, dijo, nunca la he visto. ¿La tienen guardada en sus pantalones, le respondió la chica, y si tienes tanto interés, por qué no le pides a uno de ellos que te muestre su pito? Cosa que enseguida hizo, insistentemente.

En la pubertad sus crisis de excitación aumentaron. Sin un borde corporal, sin el significante fálico del que dispone la neurosis, el goce no podía ser alojado. Pero al menos, disponía del pensamiento en imágenes. 
En conclusión, si observamos la época infantil, la prepubertad, la pubertad, vemos que el pensamiento en imágenes o pensamiento visual constituye para ella un modo de articularse al lenguaje. Es el esbozo de una solución singular que le permite anudar lo simbólico con lo imaginario. Probablemente ese anudamiento no le permite construir un saber hacer con lo real, pero le permite habitar el lenguaje. Le permite hacer la difícil operación del pasaje de lalengua a un modo de habitar el lenguaje, pese a las consecuencias de la forclusión del agujero.

\section{Soluciones}

A los 16 años se producen dos acontecimientos que le permiten una solución. Una, responde al pensamiento con imágenes. La otra, a la construcción del cuerpo.

Desde la pubertad, las crisis de excitación -llamados por ella ataques de nervioshabían aumentado mucho. A los 16 años fue a un parque de diversiones y encontró que un juego llamado el Rotor, con toda la hiperexcitación que le producía al hacer girar violentamente su cuerpo, la calmaba. Dos cosas la calmaban: o bien la hiperexcitación o bien la inmovilidad.

Buscando solución a sus crisis, y sin poder resolverlas, una vez casualmente debió acompañar a sus compañeras al servicio religioso, y las palabras del pastor le parecieron enigmáticas: "Llamad" dijo, "y El os responderá". Quién? Dijo ella. "Yo soy la puerta, el que por mí entrare será salvo", dijo el pastor, y agregó "Ante cada uno de vosotros hay una puerta que da al cielo. Abranla y estarán salvados". Desde ese momento se concentró en buscar puertas: la del armario, la del baño, la del establo, todas las puertas disponibles. Hasta que encontró que estaban construyendo un mirador cerca de su casa:

(...) del edificio sobresalía una pequeña plataforma, me subí a ella, y allí estaba la puerta! (...) me inundó una sensación de alivio. Por pirmera vez en muchos meses me sentí segura y esperanzada respecto del futuro. ¡La había encontrado! La puerta que daba a mi cielo. Un símbolo visual. Todo lo que tenía que hacer era pasar por esa puerta. Por supuesto, en esa época no sabía que mi pensamiento era visual y que necesitaba símbolos concretos para elaborar los conceptos abstractos (...) En los días y meses que siguieron visité a menudo el mirador (o Nido de cuervo como lo llamaban los carpinteros) Cuando entraba en él me tranquilizaba (...) En la intimidad del Nido de cuervo pensaba en mi niñez, en la confusión, el esfuerzo por comunicarme, los conflictos (...) Una y otra vez era atraída por el Nido de cuervo. Cuando estaba allí sentía como si fuera a descubrir algo sobre mí misma. Y lo hacía(Grandin, 2006, p. 76).

Esta primera solución está dada por su pensar en imágenes, y además le proporciona la posibilidad de un aislamiento que le permite alejarse de los estímulos humanos. 
A los 17 años fue la primera vez que pasó unas vacaciones alejada de sus padres y de su escuela, en la granja de su tía Ann. Allí hizo los trabajos típicos de campo, pero llamó principalmente su atención la manga del ganado, en la cual se reproducía aquello que ella había fantaseado: una máquina que inmovilizaba a las vacas para ser vacunadas o bien para el matadero. Pasó horas pidiéndole a su tía que accionara la palanca para quedar inmovilizada en esa máquina.

Al llegar de sus vacaciones, rápidamente se puso a construir una máquina que reprodujera el mecanismo, a la que llamó la máquina de apretar. Esa máquina fue la solución definitiva para sus ataques de nervios: cada vez que aumentaba la excitación, aquélla que le resultaba insoportable desde la infancia pero principalmente desde la pubertad, se metía en la máquina de apretar y quedaba totalmente inmovilizada al accionar la palanca. La pacificación era instantánea.

Esa máquina causó gran conmoción en el colegio de montaña donde estaba, donde los alumnos vivían durante la semana. Los profesores y compañeros interpretaban esa máquina con simbolismo sexual, o como signo de un empeoramiento de su ya extraño comportamiento previo. El psicólogo del colegio, luego de carraspear mucho, le dijo: "Temple, no tenemos un problema de identidad, no es cierto? Quiero decir, no creemos ser una vaca o algo así, no es cierto?”. -“Está loco? Por supuesto que no creo ser una vaca o algo así. Usted cree ser una vaca?”, le preguntó ella, cosa que irritó mucho al psicólogo, quien rápidamente se comunicó con sus padres para informarles, y con el departamento de psiquiatría, quienes también consideraron que su aparato era malsano y que no debía ser usado. Intentaron privarla del aparato, lo cual aumentó al máximo sus ataques de nervios. El tema produjo un escándalo en el colegio, pero como eran sus últimos meses antes de graduarse, se resolvió con el final de las clases.

El antecedente para la construcción de la máquina había sido un profesor que ella admiraba mucho, que la había introducido a la construcción de dispositivos de la física, maquetas y máquinas. Al iniciar sus estudios universitarios, prosiguió sus conversaciones con él. Allí se le ocurrió que, para evitar un nuevo escándalo y que la máquina fuera aceptada en la universidad, podía hacer un experimento científico con ella. Su tesis universitaria tuvo como objetivo demostrar estadísticamente que su máquina de apretar servía para tranquilizar no sólo a ella, sino también a las demás personas. Los resultados que obtuvo le permitieron aprobar su tesis, construir una máquina mejorada, y que la universidad aceptara que ella tuviera la máquina en su habitación.

Tanto el uso de la hiperestimulación (girar en círculos en su infancia, el rotor en la adolescencia) como la inmovilización del cuerpo o el aislamiento (la fantasía de máquina, el mirador, luego la máquina) como modos de calmarse, muestran en los distintos momentos de su vida sus dificultades con el borde y por lo tanto, la construcción del cuerpo. En su libro, ella remarca la solución definitiva que constituyó primero encontrar esa puerta, y luego, la construcción de su máquina de apretar, un antes y un después en su vida. 
El Nido de cuervo, producto del pensamiento en imágenes, le permite una solución imaginaria que demarca un interior-exterior -la puerta versus el mundo de las personas-, es decir la construcción de un borde que funciona como suplencia del borde entre el sujeto y el Otro. Como dijimos antes, la forclusión del agujero impide la constitución estructural del borde y por lo tanto, del cuerpo. Entonces, este borde de artificio que construye como suplencia, tiene un funcionamiento efectivo, que la calma, y que le permite la elaboración de construcciones simbólicas con las que puede enfrentar mejor el mundo de la gente.

La máquina de apretar va más allá: permite localizar un exceso de excitación, un goce que ningún instrumento simbólico o imaginario previo podía alojar. En ese sentido, es un borde que anuda algo de lo real del goce con lo imaginario, y por lo tanto, funciona como la suplencia del borde imaginario-real que constituye el cuerpo.

Estas soluciones tienen el carácter de una suplencia o un sinthome, en la medida en que son soluciones definitivas: ella ya no necesitará recurrir al Nido de cuervo o a la máquina de apretar durante el resto de su vida. Las usa durante esos años, y luego aquella solución a la que llegó, queda inscripta. Algo queda anudado con esas suplencias, y pese a que después pueda tener otras dificultades e incluso algunas crisis de excitación, funcionan como algo a lo que ella puede recurrir subjetivamente.

La historia de Temple continúa, pero no nos dedicaremos a eso aquí. Por ejemplo, podemos mencionar que luego de varias investigaciones en la granja de su tía, inventó una máquina de apretar para el ganado, que mejoraba en mucho las existentes, y que le valió vender su invento a las grandes haciendas estadounidenses y ganar mucho dinero con ello. También podemos mencionar que terminó sus estudios universitarios sobre psicología animal a la que se dedicó mucho tiempo. Y también, principalmente, que dedicó sus descubrimientos sobre sí misma al trabajo con padres de niños autistas, esclaréciendolos con sus libros autobiográficos y sus conferencias sobre la subjetividad de un autista. 


\section{Referencias}

Grandin, T. (2006). Atravesando las puertas del autismo. Paidós.

Lacan, J. (1992). El Seminario, Libro 20. Paidós.

Laurent, E. (2013). La batalla del autismo. Grama. 